Fernando Quesada López

\section{Templo. Máquina. Caravana El teatro y la ciudad en la Italia del siglo XX}

Keywords: situation, city, temporality, technics, theatre

Between 1965 and 1975 there was a very intense debate in Italy about the theatrical architecture, the theatre building and its urban, social and political role. It was articulated around three terms that assume three ways of relation between the theatrical building and the city: the temple, the machine and the caravan. That debate, of an unusual wealth, was completely absent from the official historiography of Italian and European architecture, despite its intensity and the importance of all its protagonists for the architectural culture of the twentieth century. Many of the most prominent architects, critics and historians intervened in this debate with unbuilt competition proposals, opinions or rigorous analysis. One of the most active was Guido Canella, with a broad career as theatre architect and a scholar of theater culture himself. He organized a design studio at the Politecnico di Milano in 1965, accompanied by lectures, panel discussions and group performances by international avant-garde artists. All this material was gathered in a publication edited by Guido Canella that inaugurated this debate, called The Theatrical System in Milan, and to which all protagonists referred at some point of their respective interventions. In addition to Guido Canella, other personalities such as Bruno Zevi, Maurizio Sacripanti, Constantino Dardi, Mario Manieri-Elia and Manfredo Tafuri, intervened marking a cultural reef that remains widely forgotten today.

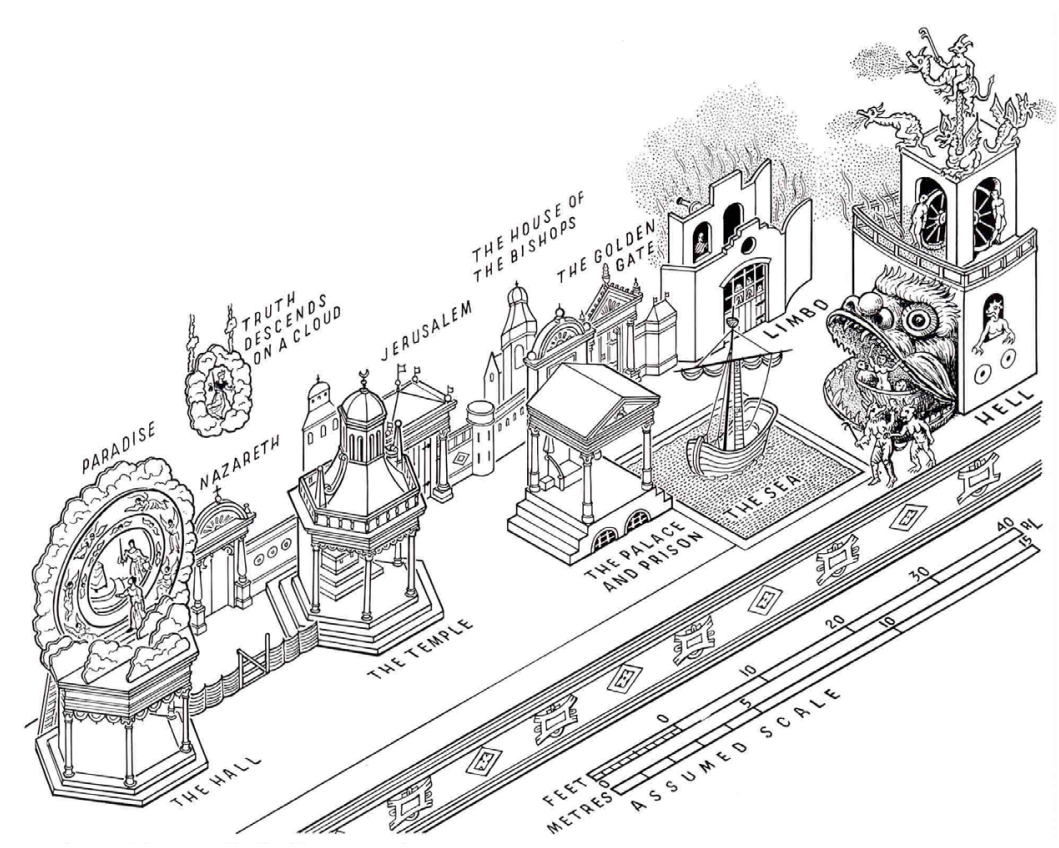

Figura 1. El Misterio medieval de Valenciennes de 1547 , mostrando las escenas bíblicas dispersas configurando una ciudad paralela. Fuente: The Development of the English Playhouse, Ithaca, New York: Cornell University Press, 1973.
G uido Canella publicó en 1966 un libro llamado Il sistema teatrale a Milano, que analizaba el desarrollo histórico de lo que llamó "sistema", en referencia a la relación entre tipo arquitectónico, forma urbana y uso social del espacio teatral (Canella 1966: 7-17, Canella 1969: 9-19). Canella diferenció drásticamente el punto de vista del arquitecto de aquel del director, escenógrafo o autor dramático. A los segundos, los artistas de la escena, corresponde una visión interna, referida al espectáculo mismo, al aparato escénico, a los requisitos técnicos y a la estética propia de esa forma de arte. Al arquitecto una visión más relacional y amplia, la establecida entre el edificio, la ciudad y el medio social, que se encarna en la relación arquitectónica específica entre escena y platea como una miniatura del modelo que puede así ensayarse a escala, pero con el deseo de superarla. Canella estableció una clasificación en tres tipos de espacio teatral en función de su relación con la ciudad al asumir la posición del arquitecto, no la del hombre de teatro: el "teatro-templo", el "teatro-máquina” y el "teatro-móvil”. 


\section{El sistema teatral}

En la ciudad existe siempre una teatralidad social difusa, no necesariamente artística ni institucional, que el edificio teatral encapsula e institucionaliza entre sus paredes. Esta teatralidad social es necesariamente múltiple e incluso inaprensible en términos formales, tanto como lo sea el medio social, por eso Canella habla de "sistema teatral" para designar al ámbito urbano que rodea a un edificio teatral en un ejercicio de analogía directa muy eficaz. En el vocabulario de Canella, "sistema" se refiere a un ámbito físico que supera al tipo arquitectónico del teatro y que comprende más factores, a los que un arquitecto debe prestar atención más allá de conocer y manejar las tipologías de espacio teatral a su disposición (Canella 1989: 70-93) (Figura 1). ${ }^{1}$

Esta noción es muy similar al concepto de "teatro espontáneo" manejada por Le Corbusier en 1948, que fue muy influyente tanto en la cultura arquitectónica como en la teatral de su momento, dada la importancia de su autor y la difusión que tuvo en publicaciones de amplia circulación (Le Corbusier 1950) ${ }^{2}$. En aquel texto transcrito de una conferencia impartida en La Sorbona, Le Corbusier describía con admiración escenas de sus viajes por Europa, el norte de África y Latinoamérica en las que el espacio urbano acogía manifestaciones de encuentro social no programadas a las que asignaba una fuerte carga escénica, en continuidad con las celebraciones populares, laicas o religiosas de la vieja ciudad europea consolidada. En otras palabras, Le Corbusier consideraba la calle de la ciudad tradicional, y no el edificio del teatro, como el máximo ejemplo de arquetipo espacial de la teatralidad (Figura 2). ${ }^{3}$

Tanto en el caso de Le Corbusier como en el de Guido Canella, el objetivo era sensiblemente similar: la superación del privilegio históricamente asignado a una visión estrictamente profesional y tecnicista o tipológica de la relación entre escena y platea, y su sustitución por una visión social y urbana más amplia que, conceptualmente, desintegra el tipo arquitectónico del teatro y lo disemina en la ciudad, dando lugar a teatros y a pseudoteatros indistintamente y $\sin$ jerarquías entre ellos. Para ello ambos arquitectos propusieron dos procedimientos de superación disciplinar simultáneos en sus discursos respectivos. En primer lugar, la superación del proyecto entendido como actividad de diseño al servicio de la dramaturgia escénica, es de-

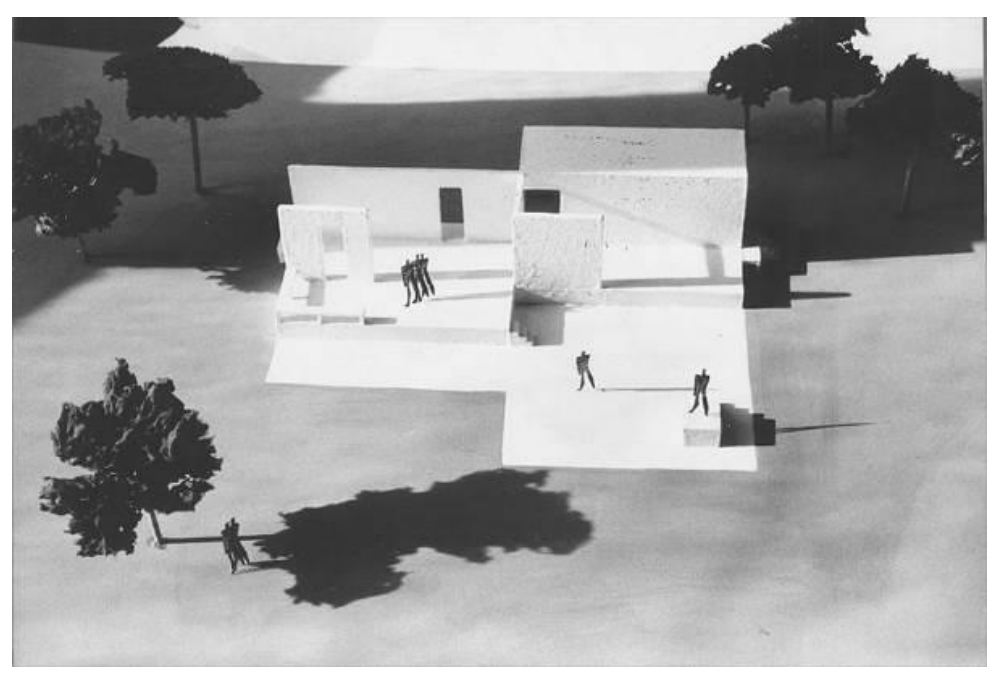

cir la superación de la escenografía como el campo de actividad propio del arquitecto. En segundo lugar, su análogo sistémico a nivel urbano, la superación del tipo teatral como el mero diseño del contenedor de una dramaturgia social ya existente, previamente escrita por los comportamientos sociales y urbanos comúnmente aceptados y hegemónicos. Desde el punto de vista del proyecto, se trata de estrategias de transposición de valores o parámetros propios de la escena hacia el ámbito arquitectónico y urbano que además contienen posibles capacidades de transgresión del orden social dominante.

Según Canella, el arquitecto de teatros debe revelar o al menos facilitar esa teatralidad social múltiple, espontánea y difusa del medio urbano, y configurar sistemas tipológicos y programáticos más complejos, más allá tanto de la propia escena como del edificio teatral. Así podrá garantizar una cierta continuidad entre las formas más espontáneas de teatralidad social (que tienden a ser efimeras y en ocasiones irrepetibles) y las más institucionalizadas del edificio teatral propiamente dicho (que siempre tienen una fuerte tendencia a la repetición ritual).

El término teatro-templo alude al periodo histórico iniciado por el establecimiento de los primeros teatros del Renacimiento y cuya culminación sería el teatro de Bayreuth de Richard Wagner de 1876 que es, según Canella, el mejor exponente de este tipo. Este se solapará históricamente con el siguiente, el teatro-máquina, que proviene de los experimentos escenotécnicos barrocos, pero que llega a su climax con el Totaltheater de Walter Gropius para Erwin Piscator en 1927. El tercer tipo, el teatro-móvil, tiene una genealogía paralela e igualmente extendida en el tiempo que hunde también sus raíces en los mismos
Figura 2. Maqueta para el teatro espontáneo del Centro Cultural de Fort-Lamy, 1960 × Fondation Le Corbusier. 

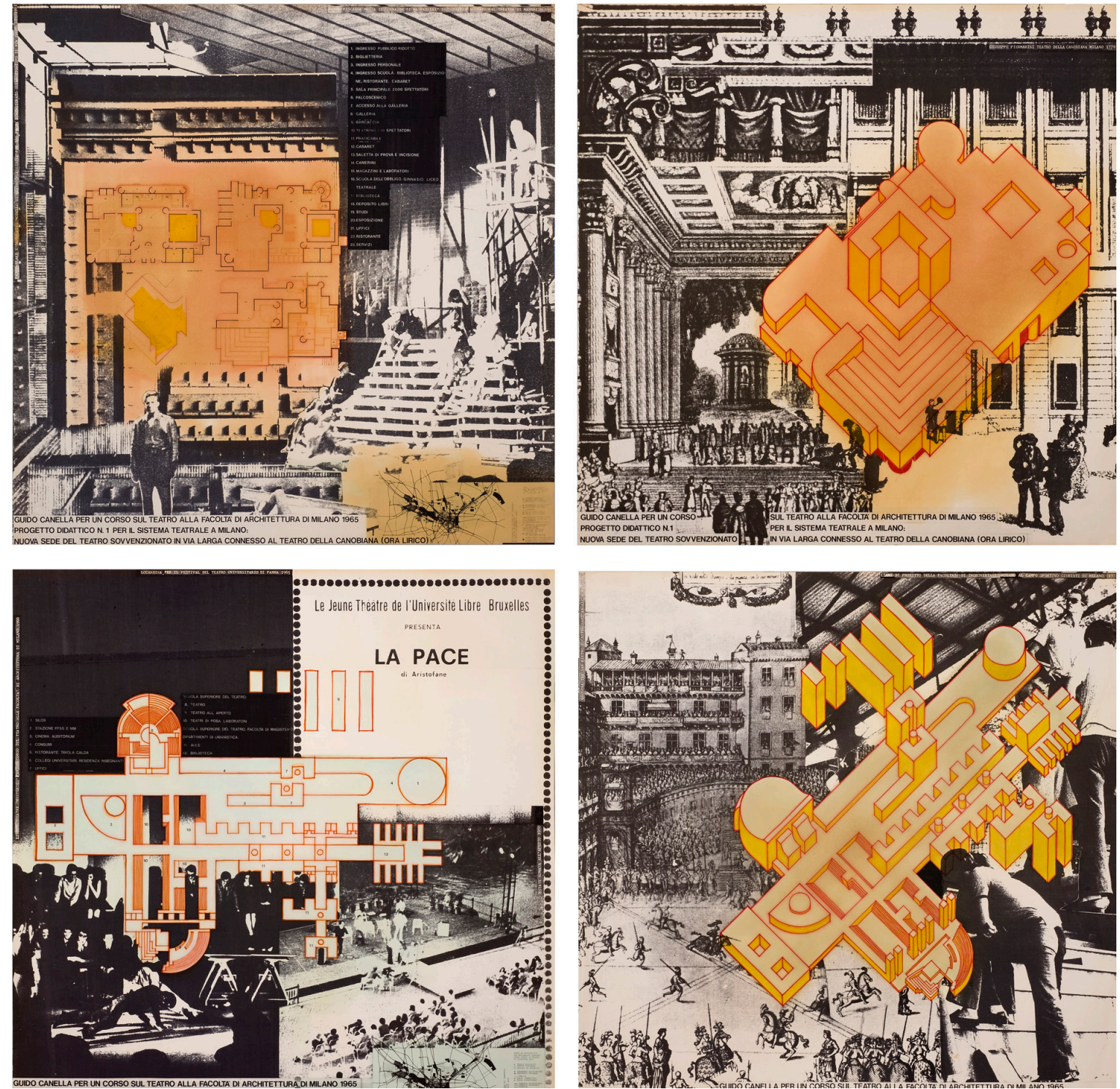

orígenes clásicos, pero con un desarrollo histórico irregular, así como un protagonismo mucho menor y una escasa visibilidad documental que hace dificil su caracterización, aunque mantuvo siempre ciertos vínculos con los otros dos tipos.

Después de Bayreuth, que culminó la Figura 3. Arriba Progetto Didattico $\mathrm{n}^{\circ} 1$, Nuevo Teatro Público en Via Larga, conectado con el Teatro Canobiana, Milán, 1965; abajo Progetto Didattico $\mathrm{n}^{\circ} 2$, Escuela de Teatro, Escuela de Pedagogía y Departamento Universitario de Ciencias Sociales en Sesto San Giovanni, Milán, 1965. Cortesía de Francesco Moschini y Gabriel Vaduva. Fondo Guido Canella del AAM Architettura Arte Moderna, Roma. visión crítica de la cultura teatral romántico-ilustrada contra el teatro de corte europeo establecido en el Renacimiento, la vanguardia teatral se concentró en tres vías fundamentales de trabajo. La primera supuso una insistencia en el teatro-templo, que experimentó con la representatividad del edificio teatral como monumento urbano y como símbolo de una forma politica determinada, incidiendo en sus aspectos de templo laico y cívico. La segunda, la máquina, consistió en ensayar nuevos modelos de espacio para el interior de la sala teatral, experimentando en las relaciones platea-escena en función de los desarro- llos de la escritura teatral y de los formatos escénicos, con especial incidencia en sus tecnologías, en renovación acelerada y permanente. La tercera, la caravana, fue la propuesta de un nuevo rol social para el teatro tras la emergencia de una nueva forma cultural de masas distintiva de las grandes ciudades y desconocida hasta entonces, que experimentó cierta eclosión con las vanguardias históricas y su fascinación por el fenómeno metropolitano. Esta taxonomía del espacio teatral en relación con lo urbano establecida por $\mathrm{Ca}$ nella fue discutida por otro autor italiano, el arquitecto e historiador Mario Manieri-Elia, que da aún más claves para una mejor interpretación de cualquier propuesta de espacio teatral por lo que se refiere, sobre todo, a su posible rol urbano, político y cívico (Figura 3).

Manieri-Elia acudió en el verano de 1975 a un seminario organizado por el Centro Internazionale di Studi di Architettura Andrea 


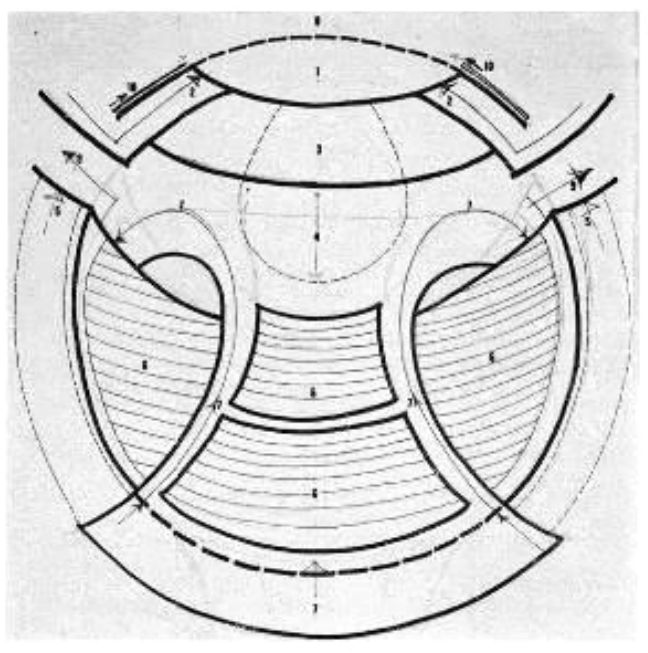

Palladio en Vicenza junto a una serie de expertos, entre los que se encontraba también Manfredo Tafuri. ${ }^{4}$ En paralelo a la triada templo-máquina-caravana establecida por Cane1la, Manieri-Elia habló de tres momentos de la cultura teatral contemporánea: el lúdico, el productivo y el ritual, de cara a abordar qué relación pudiera establecerse entre teatro y arquitectura en el nuevo marco de la cultura de masas y de consumo, ya esbozada por la vanguardia histórica y muy presente en la fecha del encuentro de Vicenza. El momento lúdico es sancionado por Manieri-Elia dogmáticamente, considerando que prescinde por completo de la arquitectura, porque la arquitectura siempre sigue una función social que es negada por la absoluta gratuidad del momento lúdico. $\mathrm{El}$ acto lúdico sería anti-arquitectónico e incluso anti-teatral en sentido estricto porque "ha perdido su función catártica" que es la propia del rito, la función principal del teatro y de su arquitectura asociada podría decirse (Manieri-Elia 1975: 379), ${ }^{5}$ para desembocar en una forma de temporalidad que excluye la dimensión ritual y con ello, su función social. Manieri-Elia distingue así claramente y con cierta crudeza lo lúdico del ritual porque el ritual está inevitablemente vinculado a "una intención funcional, busca solucionar una determinada situación critica de la colectividad" (Manieri-Elia 1975: 379), frente a la agitación lúdica en estado puro, con funciones puramente destituyentes y críticas. Manieri-Elia encuentra así en el ritual el vinculo fundamental entre teatro y arquitectura y su potencial político.

El momento o polo que denomina productivo, por su parte, es el trabajo escénico propiamente dicho, en que el discurso pasaría del ámbito teórico o de las ideas al ámbito de la práctica y a sus condiciones dentro del ciclo

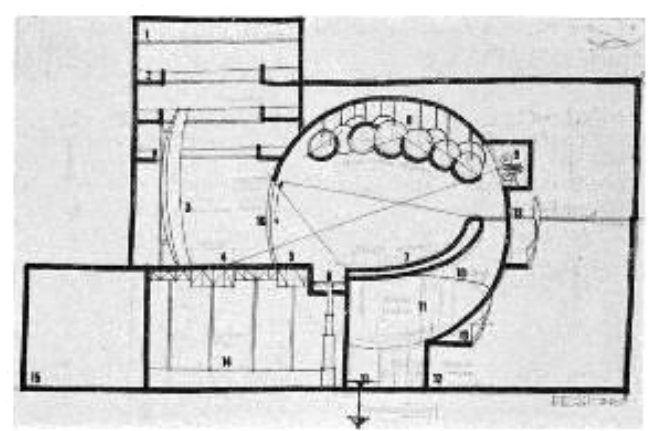

Figura 4. Proyecto de Teatro Esférico de Piero Berengo Gardin. Fuente: I Problemi di Ulisse, año XXII, vol. 10, 1969. de producción, gestión y consumo. En relación con él, el polo lúdico conlleva por lo tanto la total disolución del dispositivo, la "desaparición del teatro" (y de la arquitectura), la explosión anímica que no conduce a función social alguna de carácter ritual en una tarea improductiva en este tipo de economía simbólica que describe Manieri-Elia desde la óptica marxista. El polo productivo, en su estado de máxima intensidad escénica, conlleva por su parte la absoluta reformulación del cuerpo social mediante lo que Manieri-Elia llama el "teatro de acondicionamiento total". Para el primer caso (un ludismo desatado) da el ejemplo de Yves Klein y su teatro vacío sin actores ni espectadores, con una taquilla abierta perfectamente iluminada, un teatro en el que "se pagará a los actores por desaparecer entre la gente; el público pagará su entrada para tener derecho a una butaca vacia con nombre propio. El teatro se convierte así en una caja vacía que cumple hasta el final, y mediante pago, su propia tarea improductiva" (Manieri-Elia 1975: 380-381). Para el segundo caso (un productivismo total) da el ejemplo de una propuesta de espacio escénico esférico de Piero Berengo Gardin, derivada paradójicamente del espacio propuesto por Antonin Artaud, que acondiciona psicológicamente al espectador mediante un artefacto tecnológico implacable, como se sigue del texto descriptivo que lo acompaña: "La envolvente esférica reconduce al espectador durante su 'nutrición espectacular' (escenario igual a placenta) a una condición hipotética 'uterina', en la que dicha envolvente 'protege' al espectador" (Berengo Gardin 1969: 25-31) (Figura 4). ${ }^{6}$

En ambos casos (Klein y Berengo Gardin) el resultado de la supuesta disolución es el espectáculo reforzado bajo dos formas opuestas pero finalmente confluyentes en su condición 
Figura 5. Arriba Progetto Didattico ${ }^{\circ} 3$, Escuela Superior y Edificio de Exposiciones en Lissone, Milán, 1965; abajo Progetto Didattico $\mathrm{n}^{\circ} 4$, Teatro, Escuela al aire libre y Escuela Primaria en Novegro di Segrate, Milán, 1965. Cortesía de Francesco Moschini y Gabriel Vaduva. Fondo Guido Canella del AAM Architettura Arte Moderna, Roma. meramente espectacular. En el primer caso, el viejo templo burgués completamente vaciado de sentido y cuya función es la perpetuación pánica de su propia supervivencia como institución estéril, que no permite la emergencia de nuevos ritos, sino solo perpetuar los existentes. En el segundo, la máquina renovada de producción de shock, una incubadora de nuevos tipos de sujeto que deben adaptar su propia fisiología y aparato anímico a las nuevas tecnologías de modo permanente. Para Manieri-Elia "hay que ver en estas posiciones el intento exorcista de indicar nuevos caminos al teatro, y cuando se intenta prefigurar su forma, se llega al extremo opuesto: el de un inusitado acondicionamiento del público" (Manieri-Elia 1975: 380).

En medio de esos extremos, la arquitectura teatral habría venido oscilando hacia uno $\mathrm{u}$ otro, pero sin llegar jamás a tocarlos por- que, en caso de hacerlo y como acabamos de ver, desaparecería. El teatro-móvil, la caravana de Canella, es propuesta por Manieri-Elia como modelo posible para vincular teatro y arquitectura en una relación mutua de signo distinto respecto a su relación con el ritual: "Contra una relación tan condicionante entre máquina escénica y espectáculo, aparece el que hemos indicado como tercer tipo de teatro: el teatro-móvil en sus diferentes versiones. Pero aquí resulta más difícil hablar de arquitectura" (Manieri-Elia 1975: 386).

\section{El teatro templo}

A esta espinosa cuestión -cuánta arquitectura es necesaria para un teatro que no sea ni templo ni máquina-intentó responder Guido Canella con algunas de sus propuestas, que presentó en el libro sobre Milán de 1966, y que fueron realizadas el año anterior
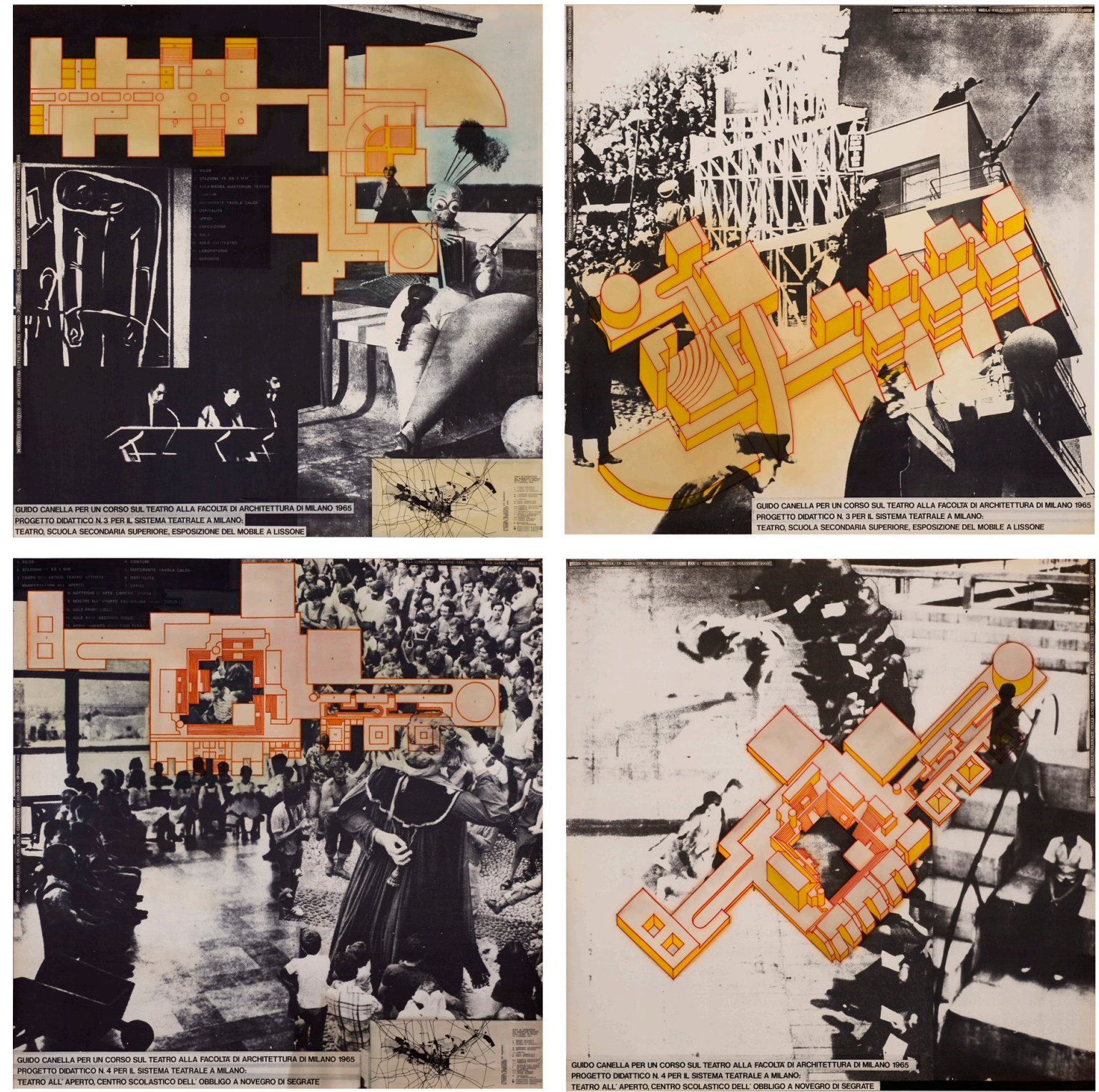
en su curso de proyectos del Politecnico di Milano. Y su respuesta fue: mucha. Sin embargo, la movilidad en relación con la ciudad fue crucial para proporcionar soluciones diametralmente distintas en el plano del lenguaje arquitectónico empleado por otros arquitectos, pero extraordinariamente similares a nivel conceptual y en sus efectos urbanos y sociales.

En su estudio sobre Milán, Canella demuestra que los desarrollos sociales del periodo de entreguerras debidos a la implantación masiva del automóvil dieron como resultado una transformación tanto de los teatros burgueses centrales como de los pequeños espacios escénicos que rodeaban el centro de Milán. Estos últimos eran frecuentados por las clases sociales trabajadoras, y su programación comprendía teatro clásico, popular, variedades, circo y teatro político (Canella 1966: 125-136). ${ }^{7}$

A esa pérdida de variedad tipológica y al aislamiento del edificio respecto al contexto urbano que esto supuso, respondió Canella con algunas propuestas de grandes piezas arquitectónicas que combinaban el teatro con el pseudoteatro, lo construido con lo no construido, el objeto arquitectónico con la textura urbana solo mínimamente materializada. Eran conjuntos edificatorios con estructura lineal y gran escala que conectaban las estaciones ferroviarias de transporte público con edificios de aparcamientos para el transporte privado. A lo largo de ese eje de movilidad se enchufaban equipamientos didácticos, como escuelas de enseñanza primaria o edificios universitarios, espacios comerciales, de producción artesanal y salas de teatro, combinando todos ellos con abundancia de espacios de graderíos al aire libre, plazas y todo tipo de pseudoteatros urbanos (Figura 5).

La respuesta de Canella no fue por tanto la ausencia de arquitectura o su disolución literal, sino todo lo contrario. Tampoco un teatro móvil o dinámico, sino un organismo arquitectónico de escala metropolitana que retomaba parcialmente algunos aspectos del teatro-templo, como su monumentalidad, estabilidad formal y capacidad de representatividad cívica. Era una arquitectura que estaba motivada por el deseo de producción de ciudad desde el teatro como actividad social de masas. Canella empleaba así la movilidad como motor conceptual de su proyecto urbano, donde lo móvil no era el teatro, sino el público, la sociedad misma y la identidad de clase, desafiando así al viejo modelo teatral por su incapacidad representativa de lo

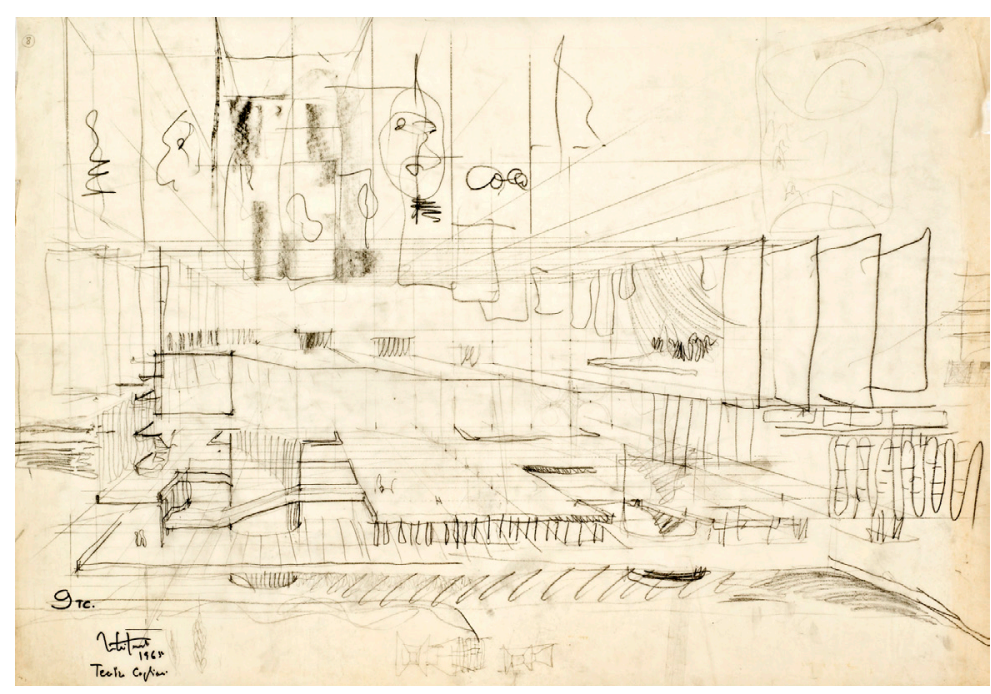

nuevo. Las propuestas de Canella, elaboradas con sus estudiantes en 1965, se enmarcarian por tanto, y con todos los matices observados, en la tradición del teatro-templo, como revisiones literalmente estalladas del tipo arquitectónico burgués y de la capacidad de la arquitectura teatral para representar a la sociedad moderna laica, democrática y policéntrica, que según el propio Canella, un único edificio estable no podría recoger en toda su complejidad.

\section{El teatro máquina}

Pero el arquetipo del teatro-máquina, que atiende no tanto a la movilidad social, sino literalmente a su propia movilidad espacial interna, también conoció un análogo revisionista exactamente en la misma fecha de 1965, con el proyecto de Maurizio Sacripanti presentado al concurso para el nuevo teatro lírico de Cagliari (Figura 6).

Este proyecto, de un virtuosismo formal y técnico pocas veces alcanzado por la arquitectura italiana del momento, proponía un gran espacio de eventos cuyo suelo y techo estaban compuestos de módulos cuadrados telescópicos, gracias a sencillos mecanismos hidráulicos, con un corredor perimetral de circulaciones y servicios. Conoció tres versiones sucesivas, en las que el espacio interior y el esquema estructural no experimentaron excesivas variaciones, siendo los cerramientos lo que fue cambiando en las versiones segunda y tercera, hasta hacer relativamente visible al exterior ese complejísimo sistema espacial móvil del interior. La evolución de las tres propuestas de cerramiento da buena cuenta del deseo por generar una fachada capaz de transmitir las ideas de incertidumbre formal a su imagen final. Ese desarrollo en variantes demuestra que la concepción del
Figura 6. Boceto inicial del espacio interior del Teatro Lírico de Cagliari, Maurizio Sacripanti, 1965. Cortesía de Francesco Moschini. Fondo Sacripanti de la Accademia Nazionale di San Luca, Roma. 


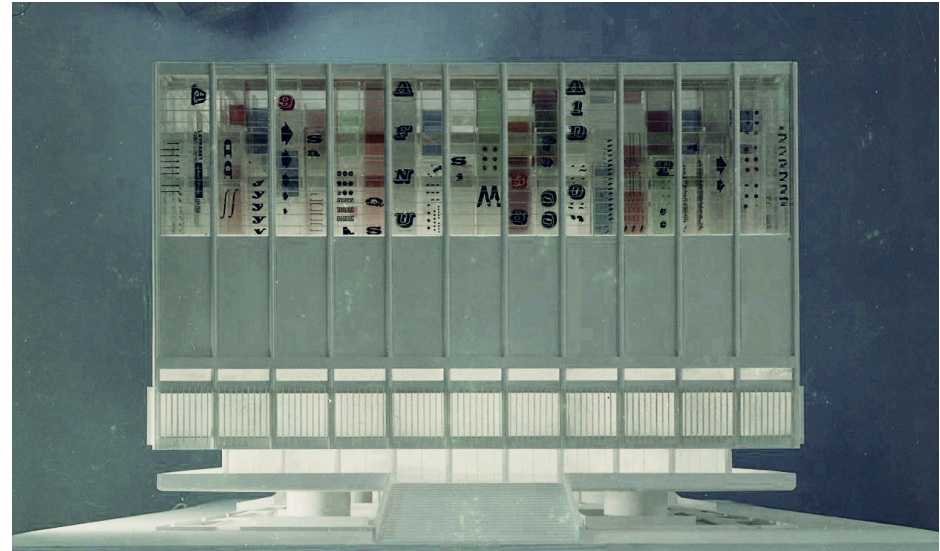

Figura 7. Versión primera (izquierda) y segunda (derecha) del Teatro Lírico de Cagliari, Maurizio Sacripanti, 1965. Cortesía de Francesco Moschini. Fondo Sacripanti de la Accademia Nazionale di San Luca, Roma.

Figura 8. Sección fugada de la versión definitiva del Teatro Lírico de Cagliari, Maurizio Sacripanti, 1965. Cortesía de Francesco Moschini. Fondo Sacripanti de la Accademia Nazionale di San Luca, Roma. espacio interior, que apenas varió durante la evolución del proyecto, experimentó ciertas dificultades para hacerse manifiesta en un plano de fachada convencional, es decir, para configurarse como un teatro-templo con un valor comunicativo coherente. Esto ponía de relieve la contradicción entre la incertidumbre de la espacialidad abierta del interior y la necesidad civica de ofrecer una fachada estable, elocuente y pertinente a esa nueva espacialidad lábil. Dicho de otro modo, se perseguía una expresión formal de la incertidumbre del espacio, una unión directa de ambiente y representación.

En la memoria del proyecto se alude a la posibilidad de que los interludios entre eventos se conviertan en eventos ellos mismos, posibilidad ofrecida por la intervención de la programación del movimiento de las piezas del suelo y el techo mediante tarjetas perforadas que controlarian este automatismo al milimetro gracias a la programación informática. La tecnología informática se ofrece como ajustado mecanismo de control del espectá-

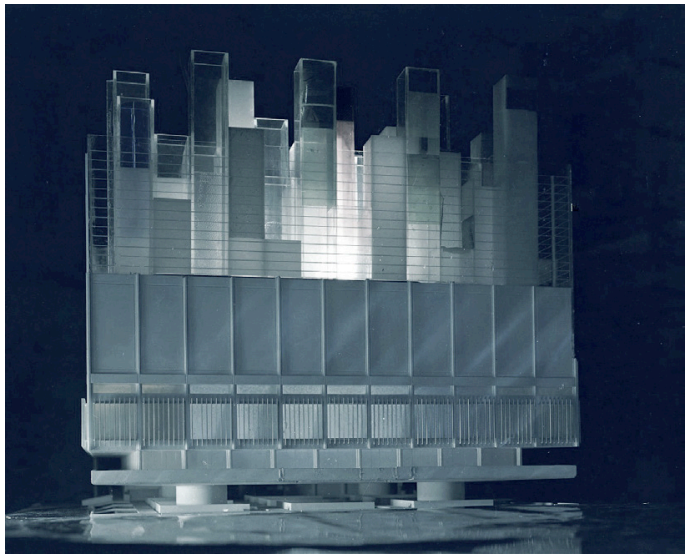

culo de masas con ese máximo aprovechamiento del espacio y del tiempo: nada debe escapar a la componente espectacular y auto-demostrativa de este imponente artefacto completamente informatizado (Figura 7). ${ }^{8}$

Los elementos que componen la platea están sustentados por una malla metálica de dos metros de altura, con pistones hidráulicos solidarios con la malla, sobre los que hay dos butacas orientables en cualquier dirección del espacio. Por lo tanto, las butacas tienen una posibilidad de orientación en principio casi infinita en la combinación de altura variable y giro variable. Además, las butacas pueden eliminarse y convertir ese soporte de suelo en escena o en superficie para cualquier uso. Un sistema análogo de prismas reconfigurables se propone para el techo a mayor escala, que puede funcionar como corrector acústico, como soporte de la iluminación o como pantalla de proyección. Sacripanti lo llamó "espacio parachoques" por su adaptabilidad (Sacripanti 1966 ${ }^{\text {: }}$ 1) (Figura 8). ${ }^{9}$

La estructura de cubierta consiste en un sistema estéreo de cinco metros de canto en todas sus direcciones que atraviesa el espacio. Los intervalos entre los elementos de esta estructura acogen los prismas del techo cuando se recogen hacia arriba, y la propia trama de celosía que compone la estructura estérea de cubierta configura el cerramiento del edificio en una envolvente prácticamente continua. Se retomaba asi la máquina teatral barroca de shock y de sorpresas mediante la tecnología de la ficha perforada del ordenador como leitmotive arquitectónico total, a la que se alude con la composición espacial general del edificio: era una gigantesca máquina cibernética productora de efectos de luz, color, sonido y ritmos dinámicos de todo orden (Figura 9).

Sacripanti se refirió a la conocida historia de la escena moderna y su crisis, especial- 


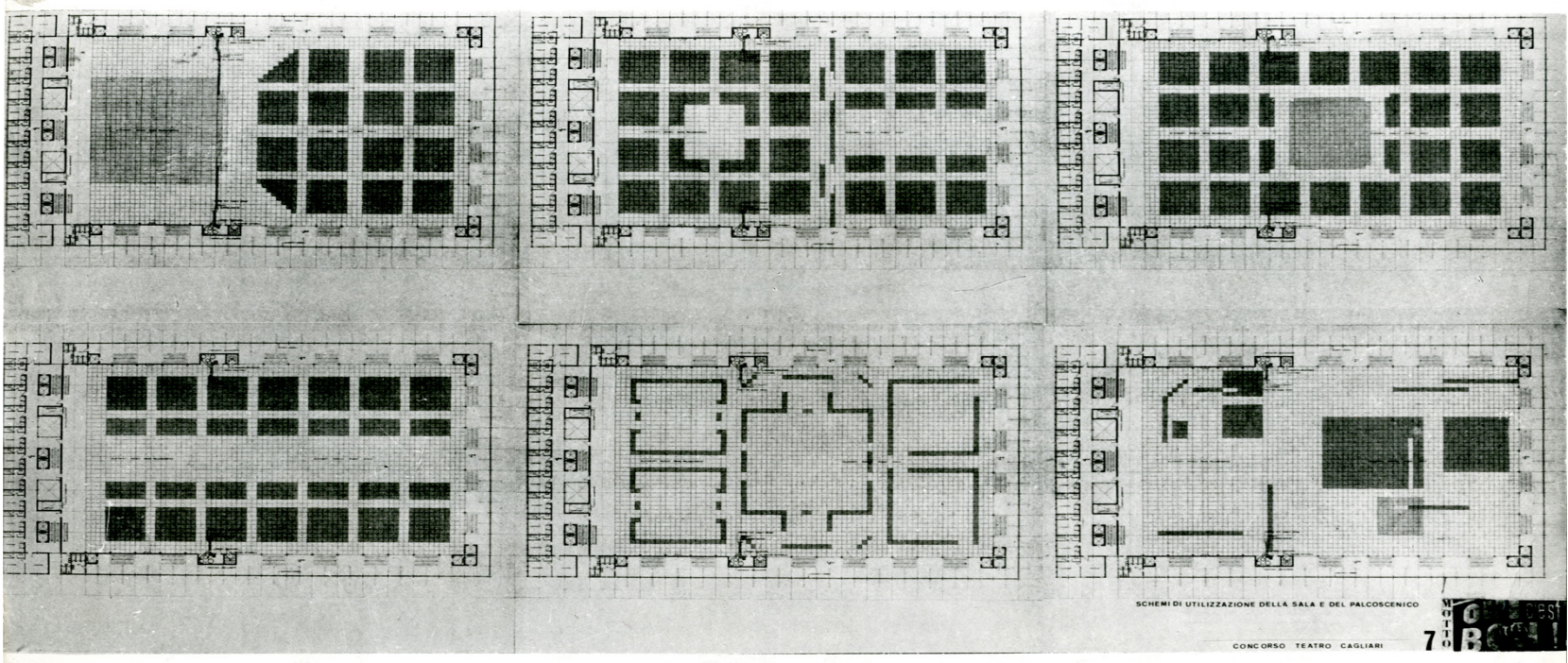

SACRIDANTI

mente sentida en esa década de 1960 (Sacripanti 1966a). Es el momento en el que la investigación historiográfica arrojó la suficiente luz como para realizar una crítica completa, empírica y sistemática de la escena moderna, lo que permitió la posibilidad de proponer paralelamente alternativas a los modelos estudiados por los historiadores. El relato crítico de Sacripanti insiste en unas afirmaciones que, para esa fecha, eran ya recurrentes. Por ejemplo, que la escena humanista del Renacimiento abandonó - para representarse culturalmente-, los espacios sacros dispersos en las iglesias y su carácter coral, a favor de una relación nueva entre platea y escena univoca, directa. Y en esa linea, propone su proyecto como un intento -otro más en la cadena vanguardista de teatros-máquina-, de superación de esa "oposición cristalizada entre sala y escena". Su herramienta proyectual es la expansión de los principios técnicos de la escena hacia la platea $y$, por extensión (aunque de modo completamente involuntario) al público, que se vería análogamente afectado por el complejo proceso de automatización del edificio (Figura 10).

Sacripanti insiste en la vía de síntesis escena-platea característica de la vanguardia teatral, haciendo hincapié en la ruptura que supuso el Renacimiento a dos niveles: el específicamente arquitectónico con la invención de la cuarta pared implícita en la separación entre la escena y el público; y el socio-político, con la aparición del artista escénico profesional y la especialización, algo que, como bien sabemos, afectó profundamente a la práctica de la arquitectura igualmente tras la ruptu- ra cultural del Renacimiento. Para Sacripanti aquella revolución cultural no siguió el camino lógico de desarrollo paralelo y convergente de ambos ámbitos (escena y platea), ya que según su breve pero elocuente y partisano relato, mientras que la escena fue incorporando con naturalidad todo el repertorio de novedades socio-culturales, técnicas y de lenguajes, la platea solo experimentó perfeccionamientos formales de su configuración física, manteniendo fijo e incluso especializando el rol del público en el rito. Toda la evolución del teatro desde el Renacimiento habría producido un incremento en la distancia entre los dos ámbitos. Desde esa voluntad de síntesis espacial, Sacripanti propone la extensión de los principios propios de la escena (mutabilidad, temporalidad y movilidad), al espacio de la platea, con la característica maniobra vanguardista

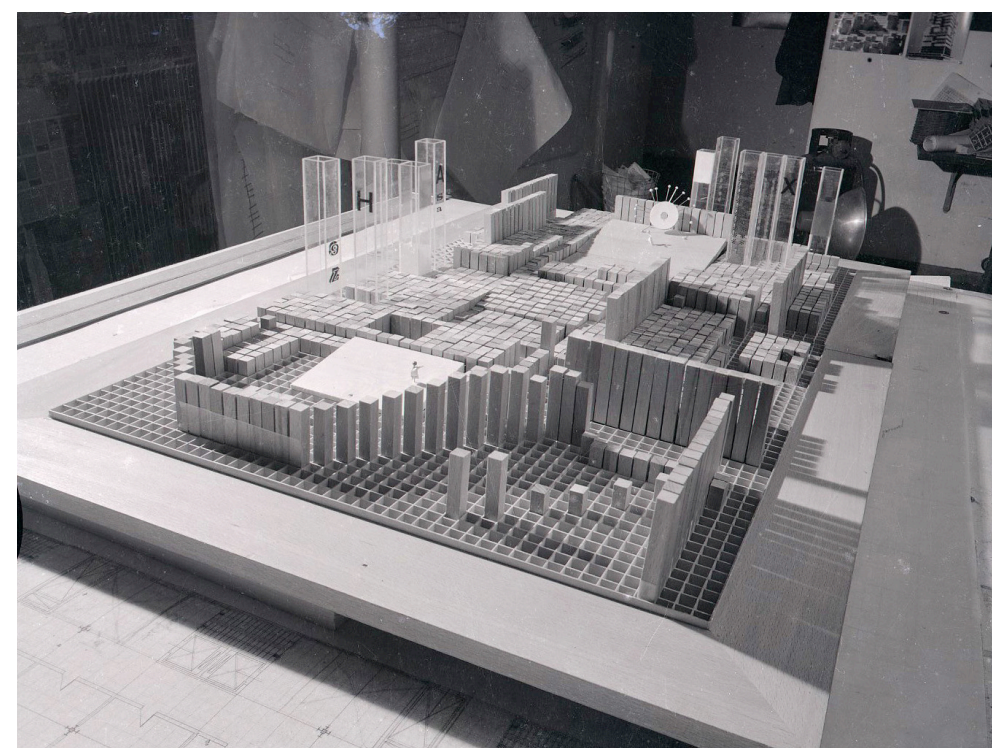

Figura 9. Esquemas variables de planta del Teatro Lírico de Cagliari, Maurizio Sacripanti, 1965. Cortesia de Francesco Moschini. Fondo Sacripanti de la Accademia Nazionale di San Luca, Roma.

Figura 10. Maqueta 1 de la versión definitiva del Teatro Lírico de Cagliari, Maurizio Sacripanti, 1965. Cortesía de Francesco Moschini. Fondo Sacripanti de la Accademia Nazionale di San Luca, Roma. 


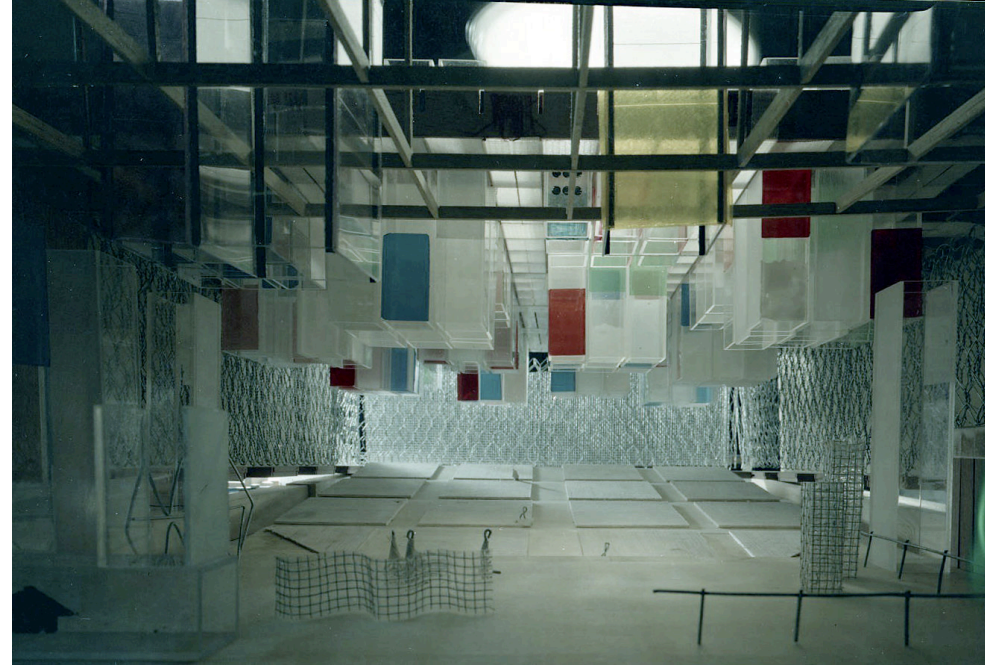

Figura 11. Maqueta 2 de la versión definitiva del Teatro Lírico de Cagliari, Maurizio Sacripanti, 1965. Cortesía de Francesco Moschini. Fondo Sacripanti de la Accademia Nazionale di San Luca, Roma.

Figura 12. Maqueta 3 de la versión definitiva del Teatro Lírico de Cagliari, Maurizio Sacripanti, 1965. Cortesía de Francesco Moschini. Fondo Sacripanti de la Accademia Nazionale di San Luca, Roma.

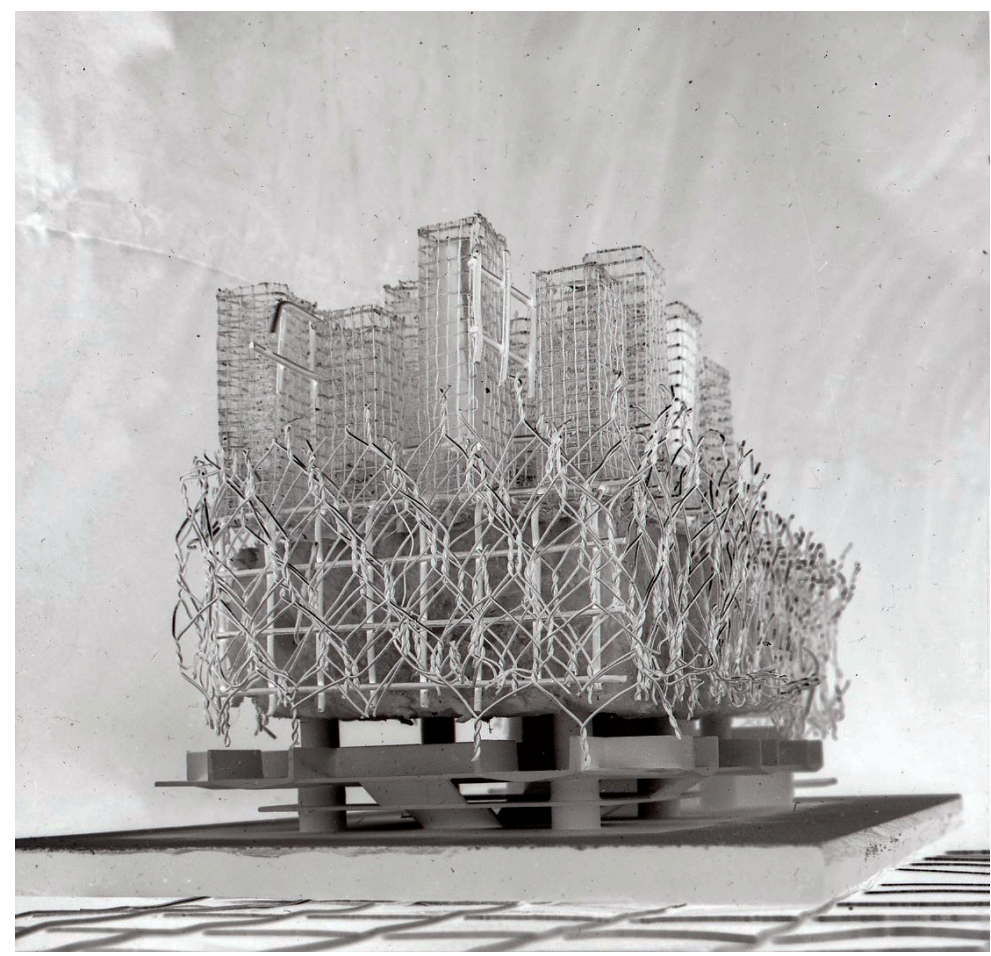

El teatro de Cagliari supone una extensión radical de las tecnologías escenotécnicas, de modo que los elementos constitutivos de toda la arquitectura del edificio se sometan a la posibilidad de maniobrabilidad. Esto convierte al edificio en su conjunto en el objeto de trabajo y de transformación de la puesta en escena, con independencia de quien detente esa capacidad de maniobrabilidad, algo que el proyecto no indica y que resulta muy problemático. La intervención de la cibernética en este proyecto, gracias a la colaboración con el consultor experto en sistemas informáticos Giovanni Pellegrineschi, abre las puertas a una interpretación que acercaría enormemente este proyecto al Fun Palace de Cedric Price, y no solo en términos de similitudes de lenguaje arquitectónico, más que evidentes, sino también en el plano ideológico, social y politico. ${ }^{10}$

Pese a la declaración de intenciones de Sacripanti, o quizás por la ambivalencia e incluso contradicción que existe entre la posibilidad de una "funcionalidad social" y el espacio de incertidumbre de los eventos, Manieri-Elia calificó a este proyecto de teatro-máquina en estado puro: "la arquitectura responde al concepto de 'permanencia' del teatro-templo y se convierte en un mecanismo disponible [...]. Y el público es considerado como la parte puramente absorbente del mecanismo: inmóvil y atónito, estará en el centro del espectáculo inesperado, sorprendente, que escapa a cualquier control por su parte. Sin posibilidad de defenderse" (Manieri-Elia 1975: 384-385).

Menos tajante en su valoración, Manfredo Tafuri interpretó este proyecto en una clave más matizada, como un claro intento de generación de una opera aperta a la Umberto Eco, un autor al que Sacripanti siguió muy de cerca. ${ }^{11}$ Para Tafuri, el proyecto empleaba un principio que llamó "organicidad figural de la estructura forma", que transmutaba en figura arquitectónica las estructuras informacionales espacializadas provenientes de la teoría de la información y la cibernética. Como consecuencia de esa operación, el edificio procuraba la "forma como destrucción del concepto tradicional de lugar", de modo que "se hacía necesaria una nueva organicidad semántica de la dialéctica entre disponibilidad de la estructura y concreción de los límites físico-expresivos programados en el acto de proyectar" (Tafuri 1966) (Figura 12).

A comienzos de los años sesenta, Italia fue uno de los centros de debate en torno a los avances de la lingüistica y la teoría de sistemas, en gran medida gracias a Umberto Eco. 
Sacripanti experimentó en varios proyectos con estructuras aleatorias de cierta escala y con la idea de lo que llamó "eventos programados". Pero no puede olvidarse que en 1964 la Trienal de Arquitectura de Milán se dedicó al tempo libero, a la nueva ideología del ocio masivo diseñado desde políticas gubernamentales (Tafuri 1982: 102). En esa fecha y años sucesivos, la cultura teatral italiana experimentó un florecimiento desde dos frentes bien distintos que encendieron los debates: el Piccolo Teatro de Milán y otros teatros experimentales de gestión pública (el medio cultural reformista de Canella), y la escena underground de Roma (el medio cultural rupturista de Sacripanti). En el primer caso el problema era el de la gestión, sujeta a las leyes de la competencia o a políticas de proteccionismo que harian hablar a la crítica de izquierdas encarnada en Tafuri de una "política democrática del tiempo libre". Para el teatro independiente romano, de Carmelo Bene a Luca Ronconi o Giuliano Vasilicò, el tema era otro bien distinto, el de la continuidad de las vanguardias internaciones de Antonin Artaud, Jerzy Grotowsky, el Living Theater o el Bread and Puppet.

Tafuri polarizó estas dos tendencias vinculándolas con dos tradiciones históricas. La culminación del proyecto ilustrado de Francesco Milizia para el caso milanés, un teatro de estado con un carácter moral y pedagógico, y la disolución del teatro de vanguardia en la ciudad para el caso romano con pequeños locales, salas periféricas, en la calle o en circos provisionales, siguiendo la vanguardia histórica cubofuturista, dadá y surrealista principalmente (Tafuri 1976: 38-39). Al polarizarse así el rito teatral, el público también lo hacía peligrosamente, segmentándose en ámbitos de interacción social cada vez más aislados entre sí. Por una parte una burguesía culta, reformista e inclusiva que tendía a incorporar en sí a las clases trabajadoras en sus gustos y hábitos de consumo; y por otra una nueva clase social urbana marcada por una identidad desdibujada, flexible y nómada, que experimentaba una forma de consumo cultural mucho más singularizada, pero que la desvinculaba progresivamente de la conciencia de clase tradicional.

\section{El teatro móvil}

La solución a ese dilema o tercera vía era, en palabras de Manieri-Elia, el teatro-móvil como híbrido entre el templo y la máquina, del que proporcionó un ejemplo destacado en su crónica. Se trata del proyecto de concurso para el nuevo teatro de Udine presentado por Costantino (Nino) Dardi y Mario Ricci en 1974, un proyecto jamás publicado en ninguna revista de arquitectura especializada ${ }^{12}$, pero mostrado y comentado en el encuentro de Vicenza por Manieri-Elia en 1975 y, solo un año después, en 1976, en un oscuro texto de Tafuri sobre la historia de la arquitectura teatral italiana (Tafuri 1976) (Figura 13).

La preocupación de Canella acerca de la disolución del espacio teatral y su consecuencia en la arquitectura fue plenamente compartida por Manieri-Elia, que también abogó por un "teatro de total desaparición" que mantuviese para si un soporte físico arquitectónico bien tramado con el tejido urbano y, por inmediata continuidad, con el medio social. Es ahí donde parece encajar a la perfección el proyecto de Nino Dardi y Mario Ricci, ya que consiste en un edificio llamado "teatro madre" ubicado en el solar destinado para el concurso, pero construido con una es-
Figura 13. Concurso para el Nuevo Teatro de Udine. Planta cota -2.40 , solución B, escala 1:200 y secciones del Teatro Madre, escala 1:200. Nino Dardi y Mario Ricci, 1974. Cortesía del Archivio Progetti IUAV, Venecia.
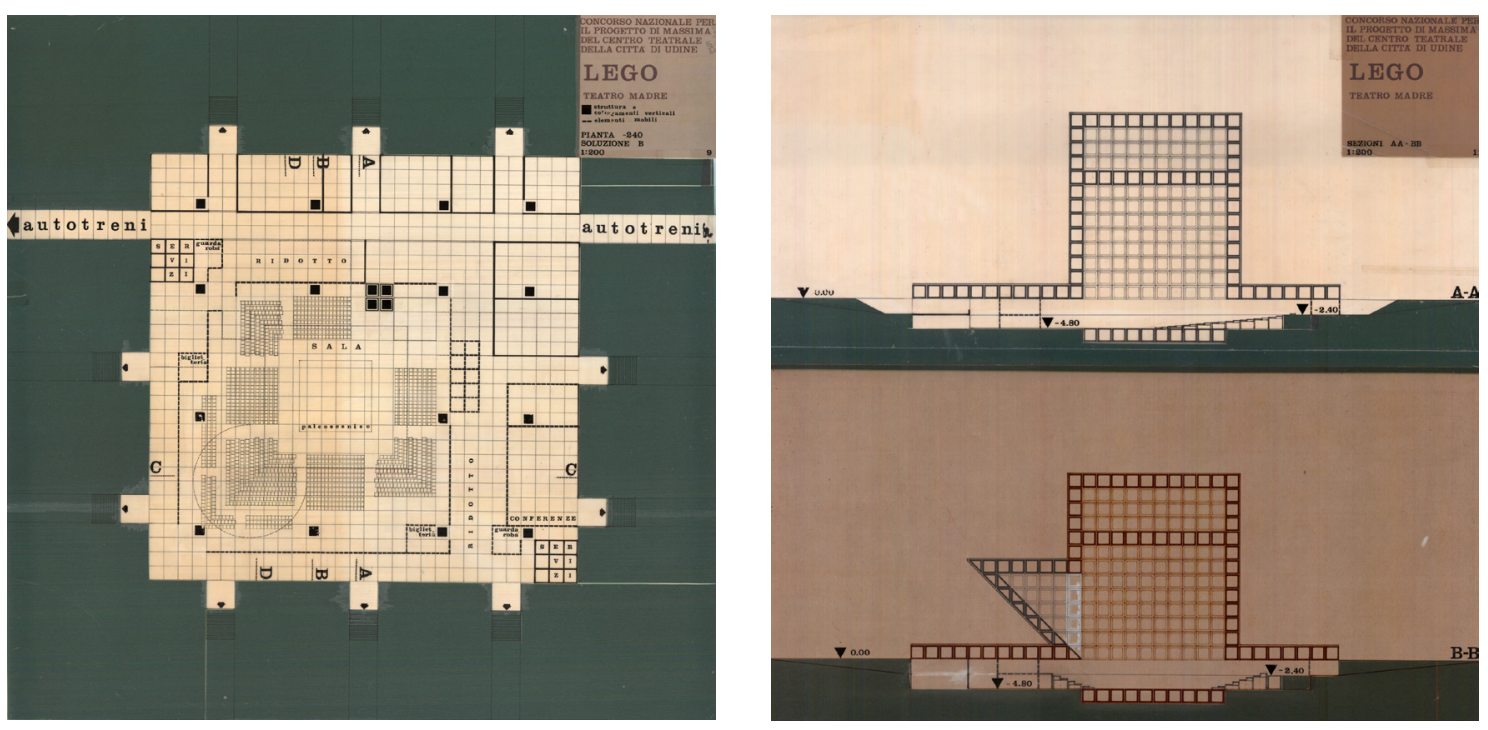


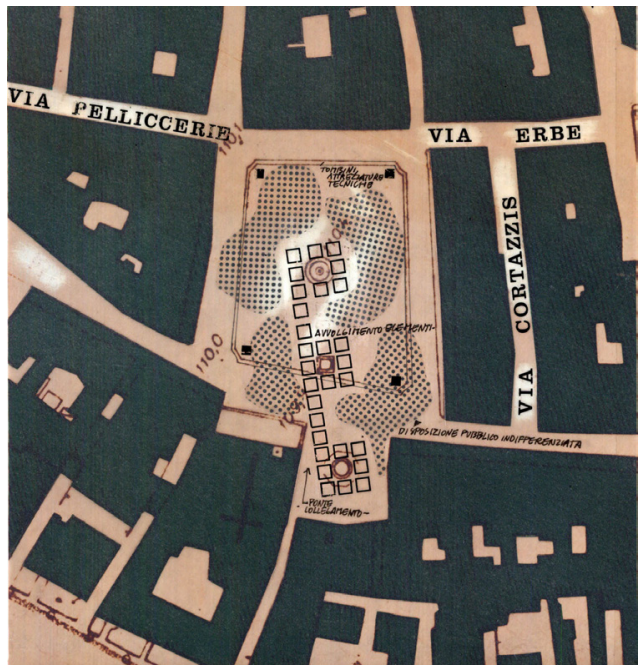

Figura 14. Concurso para el Nuevo Teatro de Udine. Planta, croquis y sección de la Piazza Mateotti, escala 1:500. Nino Dardi y Mario Ricci, 1974. Cortesía del Archivio Progetti IUAV, Venecia. tructura modular de barras de 2,40 metros de lado, desmontable y móvil, que es capaz de ocupar calles, plazas y parques mediante el traslado de esos elementos modulares en camiones articulados o autotreni. A esta configuración de barras la llamó Dardi "módulo de circulación teatral". Esa operación de montaje, traslado y desmontaje formaba parte plena del propio rito teatral, realizado para cada puesta en escena a la vista del público que, por consiguiente, participaba como espectador del rito de la construcción que lo alojaria inmediatamente después como público. El espectro del ritual, de la situación en que se desarrollaba y de su relación con la arquitectura, resultaba claramente enriquecido con esta propuesta de espacio teatral móvil.

Con el lema Lego, el proyecto de Nino Dardi y Mario Ricci proponía dicho "teatro madre" compuesto por una estructura cúbica de 28,80 metros de lado, es decir doce módulos, con una altura total de 38,40 metros, es decir dieciséis módulos, tres de los cuales se ubican bajo la cota cero procurando con ello el espacio de platea en grada fija rodeando una escena central cuadrada. A dos de sus lados y a la cota cero, se ubicaban las vías de entrada y salida de los propios módulos: los autotreni que invaden las calles saliendo en procesión del "teatro madre" para configurar escenarios efimeros. La volumetría visible era por tanto un cubo perfecto, con algunos elementos adheridos con forma de cuña o semiesfera de gran escala e impacto visual, como apéndices expresivos de un espacio platónico ideal matriz, construido a partir del módulo de 2,40 metros. Dardi fue un arquitecto fascinado por las formas platónicas, la modulación y la estructura lineal, que trabajó intensamente en la reconciliación de la forma atávica abstracta con la industria (Figura 14). ${ }^{13}$
Sin embargo, más allá del propio edificio, son los escenarios efímeros múltiples lo que verdaderamente convierte a este proyecto en una propuesta muy singular que realiza el tránsito del teatro-máquina al teatro-móvil con una naturalidad sorprendente y un minimo despliegue de recursos técnicos. Una parte muy significativa del volumen contenido en la basa del edificio se desmonta y se transporta a espacios abiertos de la ciudad, configurando escenas múltiples en la tradición de los luoghi deputati medievales. Algunos dibujos entregados al concurso muestran diversas posibilidades. Por ejemplo, para la Piazza I Maggio, se propone un escenario convencional frontal a la italiana, que ocupa el sector sureste de esta plaza ajardinada de Udine. Para la Piazza Mateotti se propone una estructura alargada en puente compuesta por tres núcleos conectados entre sí, cada uno de los cuales abraza una preexistencia: un baldaquino que cubre un pozo a un extremo, una alta columna exenta en el centro y una fuente al otro extremo, de modo que se trataria de una escena tripartita simultánea y/o alternante. Finalmente, para la Piazza Patriarcato se concibe (como en la Piazza I Maggio) un escenario elevado tradicional abierto hacia la plaza, dejando a uno de sus lados la imponente fachada de la iglesia de San Antonio como cierre escénico lateral del espacio urbano. En este escenario debía culminar una acción escénica iniciada con el transporte y montaje lineal a lo largo de la Via Treppo, proveniente del "teatro madre", por encima y debajo del cual se iba desarrollando la acción escénica, acompañando el propio movimiento del público hasta ocupar sus butacas en el escenario principal. Estas posibilidades de ocupación de la ciudad presentadas al concurso demostraban la total flexibilidad 
y variabilidad de montaje y de tipos de escena y relación público-platea, siempre motivadas por la movilidad del público y de los propios elementos constructivos del edificio. Este proyecto disuelve el teatro-máquina (un producto arquitectónico estrictamente técnico y de producción de efectos) en el espacio urbano con escenarios que producen, como afirmó Tafuri: "una relación lábil e indeterminada en el limite, entre la morfología urbana y la tipología edificatoria" (Tafuri 1976: 39) (Figura 15$)$.

\section{Conclusión}

En la triada de arquetipos espaciales y arquitectónicos que acabamos de ver con detalle, la teatralidad juega roles distintos, pero en todos ellos la arquitectura es un umbral de paso imprescindible en todo ritual. En el teatro-templo burgués la arquitectura asume una función catártica enfocada a la reafirmación de un cuerpo social bien definido y compacto, que la propia arquitectura ayuda a construir y ensalzar; un cuerpo social laico (aunque secularizado desde un origen religioso) que mediante procesos de identificación con la escena adquiere cohesión e identidad comunitaria. Estas arquitecturas suponen continuidad con ritos aceptados por la mayoría y su principal objetivo es dar legitimidad y continuidad histórica a esos ritos. El teatro-máquina opera de modo similar en tanto que legitima rituales y los ensalza, pero introduce el shock en el ritual para renovarlo y producir así, con esa operación, nuevos rituales sociales que modifican sustancialmente al sujeto. Una parte muy significativa de la vanguardia teatral operó de este modo, procurando renovaciones profundas desde el propio interior del teatro, introduciendo alteraciones en los roles intervinientes en el rito teatral y desafiando los roles previos. Con la alteración de roles el rito adquiría nuevas formas, pero el dispositivo mantenía más o menos intacto su funcionamiento como aparato de legitimación de un determinado ideal moral y pedagógico.

Sin embargo, toda historia tiene un origen y todo teatro-templo fue, en algún momento seminal y de agitación socio-política, un teatro-máquina de renovación de los comportamientos, lo que los vincula en una relación inquebrantable. El arquetipo del teatro-móvil o caravana que pone en juego Nino Dardi investiga, por su parte, un origen aún más remoto o anterior para intentar escapar de esta historia de la que siempre conoceriamos su final trágico. Se trata de aquel origen en el que los roles están aún en formación y en completa reversibilidad, la propia situación en desarrollo como rito potencial, el espacio exterior al propio dispositivo teatral, la calle y la vida diaria, produciendo ensayos menos estables y duraderos, pero más atentos a los comportamientos reales, que experimentan un sinfin de transformaciones que otras arquitecturas no permiten capturar con tanta precisión y delicadeza.
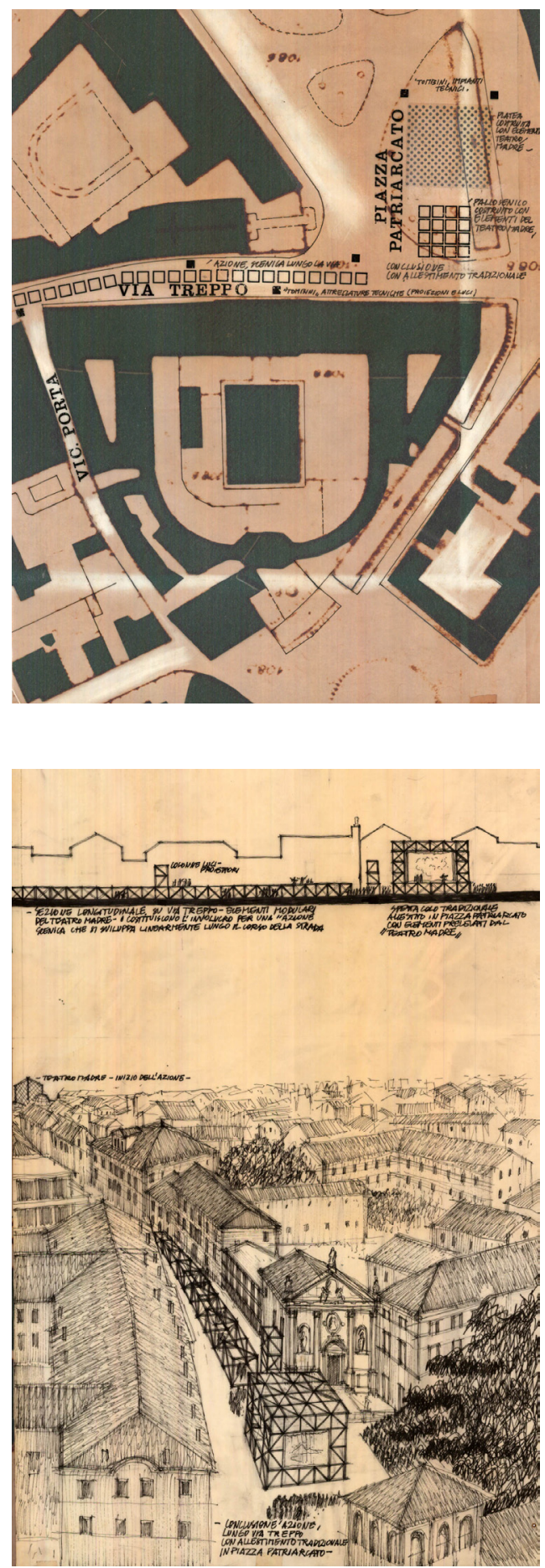

Figura 15. Concurso para el Nuevo Teatro de Udine. Planta, croquis y sección de la Via Treppo, escala 1:500. Nino Dardi y Mario Ricci, 1974 Cortesía del Archivio Progetti IUAV, Venecia. 


\section{Notas}

1 Esta categoría de sistema tomará, en la rica terminología de Canella, otros nombres en algunos de sus análisis posteriores a su libro sobre Milán, de carácter más teórico o historiográfico. Por ejemplo, Canella habló de teatros y de pseudoteatros explicando el conjunto de similitudes y diferencias entre estos dos modelos de espacio público. Los primeros son los edificios que responden al concepto de tipo arquitectónico teatral en sentido estricto. Los segundos son espacios urbanos como plazas, espacios didácticos, espacios asociativos y espacios representativos cívicos o religiosos.

2 El texto logró su máxima difusión en los círculos arquitectónicos con su edición abreviada en las publicaciones en varios idiomas del Congreso Internacional de Arquitectura Moderna CIAM VIII de Hoddesdon, celebrado en1951, tres años después de la conferencia de Le Corbusier de La Sorbona. La edición inglesa The Heart of the City, fue publicada por Lund Humphries \& Co. Ltd., en Londres, y la española El corazón de la ciudad, por Hoepli S. L. en Barcelona, ambas en 1955 con edición de Ernesto Nathan Rogers, Josep Lluis Sert y Jacqueline Tyrwhitt.

3 Para encuadrar estas manifestaciones sin coerciones físicas ni psíquicas, Le Corbusier propuso en 1960 unos teatros espontáneos para el Centro Cultural de Fort-Lamy, en el Chad, con espacios solamente formalizados con suelos equipados y superficies verticales (muretes, parterres o incluso pantallas de proyección), que dejarian de funcionar como marco o límite escénico una vez acabada la acción en curso, pasando a ser simplemente elementos arquitectónicos de organización difusa del espacio urbano.

4 El seminario, con el título L'Architettura teatrale dal Palladio ad oggi, contó con veintidós ponentes internacionales y todos ellos excepto Manieri-Elia y Tafuri se centraron en la historia del teatro desde el Renacimiento hasta el final del siglo XIX. La desproporción en la atención de los historiadores a los diferentes periodos históricos resulta notable y evidente. Manieri-Elia y Tafuri fueron los dos únicos ponentes que centraron en el siglo XX sus aportaciones a aquel foro. En aquel encuentro Manieri-Elia impartió una conferencia llamada Il teatro moderno que retoma el debate abierto por Canella y que, dada la condición de historiador marxista de Manieri-Elia, se ve profundamente enriquecido en sus aspectos ideológicos.

5 Existe versión castellana: El teatro moderno. En: Carrer de la Ciutat, $\mathrm{n}^{\circ}$ 12, Barcelona 1980, pp.: 28-36. Se ha consultado la edición original italiana.

6 Berengo Gardin aparece en los créditos de la revista como publicista y defiende en su propuesta un teatro mediático de shock en la línea de Gropius y Piscator, que confronta con los medios de masas audiovisuales con un edificio esférico derivado del espacio escénico de Artaud.

7 Durante ese periodo, y seguido de la posguerra, los teatros centrales adquirieron, con algunas excepciones, una tendencia estrictamente co- mercial, y los pequeños cinema-teatro de la periferia se transformaron en salas de cine con importantes transformaciones arquitectónicas, como la completa desaparición de los equipos escenotécnicos y la excavación de espacios subterráneos para lograr espacios comerciales ganados a estos edificios.

8 Tanto es así que se defiende para el proyecto no solamente una gran variedad de usos posibles, tales como teatro, congresos, exposiciones, mercados, ferias o manifestaciones politicas, sino que el espacio pudiera funcionar sin interrupciones de horario, de temporada o de hábitos sociales de consumo de ocio masivo. $\mathrm{Ni}$ siquiera los tiempos de cambios de espacio, gracias a los movimientos de las piezas prismáticas que componen suelo y techo, quedan fuera de la posibilidad de ser un evento susceptible de ser experimentado por el público en estado de shock admirativo.

9 Este proyecto fue ampliamente publicado en Italia y Francia. En Italia, además de la extensa reseña de Domus Sacripanti 1966a, apareció en Zevi 1965, Zevi 1966, Sacripanti 1966b y Fullaondo 1968.

10 La colaboración de Cedric Price con Gordon Pask, experto en cibernética, data de la misma fecha aproximada que la de Maurizio Sacripanti con Giovanni Pellegrineschi, entre 1963 y 1965.

11 Sacripanti estuvo muy próximo también a Bruno Zevi, que publicó algunos de los escritos de este arquitecto romano en relación con la semiótica de Umberto Eco (Sacripanti 1971 y 1974).

12 Junto a Dardi y Ricci, colaboraron en el proyecto de Udine Giovanni Morabito, Franz Prati y Ariella Zattera. Mario Manieri-Elia fue también colaborador ocasional de Dardi en su estudio.

13 Sobre Nino Dardi existe una monografía excepcional (Moschini 1976).

\section{Bibliografia}

Berengo Gardin, Piero. 1969. Teatro? En: I Problemi di Ulisse, año XXII, vol. 10: 25-32.

Canella, Guido. 1966. Il sistema teatrale a Milano, Bari: Dedalo Libri.

Canella, G. 1969. Il nuovo teatro cerca la città. En: I Problemi di Ulisse, año XXII, vol. 10: 9-19.

Canella, G. 1989. Teatri e pseudoteatri. En: Zodiac, $n^{\circ} 2: 70-93$.

Fullaondo, Juan Daniel. 1968. Agonía, utopía, renacimiento. En: Nueva Forma, $\mathrm{n}^{\circ} 28$.

LE CoRbusier. 1950. Le théâtre spontanè, en André Villiers y André Barsacq (eds): Architecture et dramaturgie. Bibliothèque d'Esthétique, Paris: Flammarion.

Manieri-Elia, Mario. 1975. Il teatro moderno. En: Bollettino del Centro Internazionale di Studi di Architettura Andrea Palladio, vol. XVII, Vicenza: 379-393.

Moschini, Franceso. 1976. Costantino Dardi. Semplice, lineare, complesso, Roma: Editrice Magma.

SACRIPANTI, Maurizio. 1966a. Il total teatro di Maurizio Sacripanti. En: Domus 437: 1-11. 
SACRIPANTI, M. 1966b. Théâtre total. En L'Architecture d'Aujourd'hui, n' 128 : 13

SACRIPANTI, M. 1971. Città di frontera. En: L'Architettra Cronache e Storia, $\mathrm{n}^{\circ}$ 187: 56-59.

SACRIPANTI, M. 1974. Maurizio Sacripanti sulla linguística architettonica. En: L’Architettra Cronache e Storia, $\mathrm{n}^{\circ}$ 230: 531-533.

TAFURI, Manfredo. 1966. Opera aperta e spazio polivalente. En: Grammatica-Teatro, $n^{\circ} 2$.

TAFURI, M. 1976. Il luogo teatrale dall'Umanesimo ad oggi. En: Teatri e Scenografie, Milán: Touring Club Italiano: 25-39.

TAFURI, M. 1982. Archittetura italiana 1944-1981. En: Storia dell'Arte Italiana VII. Il Novecento, Turin: Einaudi.

Zevi, Bruno. 1965. Un concorso concluso con sei voti contro cinque. Nasce in Sardegna il teatro in condominio. En l'Espresso.

Zevi, Bruno. 1966. Concorso nazionale per il teatro di Cagliari. En: L'Architettura. Cronache e Storia, $\mathrm{n}^{\circ}$ 123: 582-591.
Artículo publicado previamente en inglés con el título "Temple, Machine, Caravan" en AAA Italia, dic. 2017, pp. 40-59. Progettare il mutevole. Nuovi studi su Maurizio Sacripanti. Número especial. 